\section{AUTOIMMUNE-ASSOCIATED GENE CLEC16A REGULATES NLRP3 BUT NOT AIM2 INFLAMMASOME PATHWAY IN HUMAN MACROPHAGES}

WMM Li, ALY Yim*, VSF Chan, CS Lau. The University of Hong Kong, Department of Medicine - Division of Rheumatology and Clinical Immunology, Hong Kong, Hong Kong S. A.R

\subsection{6/lupus-2017-000215.351}

Background and aims C-type lectin domain family 16 member A (CLEC16A) has been associated with autoimmune diseases such as systemic lupus erythematosus, multiple sclerosis and type I diabetes in various genome-wide association studies. Subsequent studies revealed that mouse/human CLEC16A and its Drosophila homolog endosomal maturation defective isoform A (EMA) are involved in different aspects of autophagy, the regulated degradation of cellular components that are in excess or dysfunctional. Crosstalk between autophagy and inflammasome activity of innate immune responses has been reported and inflammasomes are activated in various autoimmune diseases. We thus sought to investigate the role of CLEC16A in inflammasome pathway in this study.

Methods Functional genetic studies of CLEC16A in NLRP3 and AIM2 inflammasome pathways using monocyte-derived macrophages isolated from peripheral blood mononuclear cells of healthy individuals were performed.

Results During induction of NLRP3 inflammasome pathway by nigericin, a knockdown of CLEC16A using specific siRNAs inhibited secretion of interleukin-1 $\beta$ (IL-1 $\beta$ ), an inflammasome pathway effector. Its secretion during AIM2 inflammasome induction by intracellular dsDNA poly(dA:dT) however was not affected in the siCLEC16A group. The induction of NLRP3 mRNA level upon lipopolysaccharide stimulation was suppressed in the siCLEC16A group. No significant changes in mRNA levels was observed in other selected genes of NLRP3 inflammasome pathway, namely the adaptor protein ASC, interleukin-1 converting enzyme caspase- 1 and precursor proIL-1 $\beta$.

Conclusions These data suggest that CLEC16A regulates NLRP3 but not AIM2 inflammasome pathway and affects IL$1 \beta$ secretion in part via NLRP3 level. The mechanism involved and its association with autoimmune diseases such as systemic lupus erythematosus remains to be elucidated.

\section{FROM ANIMAL MODELS TO HUMAN - A PHENOTYPIC AND FUNCTIONAL STUDY OF PDCS}

'ZZ Zhou, ${ }^{1} \mathrm{M}$ Jianyang, ${ }^{2} \mathrm{Q}$ Rong, ${ }^{1} \mathrm{~S}$ Nan*. ${ }^{1}$ Renji Hospital- School of Medicine- Shanghai Jiaotong University, Shanghai Institute of Rheumatology, Shanghai, China; ${ }^{2}$ Shanghai Institutes for Biological Sciences SIBS and Shanghai Jiao Tong University School of Medicine SJTUSM- Chinese Academy of Sciences CAS, Institute of Health Sciences, Shanghai, China

\subsection{6/lupus-2017-000215.352}

Background and aims To study the role of plasmacytoid dendritic cells(pDCs) in the pathogenesis of systemic lupus erythematosus(SLE)

Methods Totally 9 mouse strains were studied including NZB, NZW, NZBW F1, MRL/lpr, MRL/Mp, BXSB/Mp, BXSB.B6. Yaa, B6.SLE1.2.3 and C57BL/6. Spleen, thymus, bone marrow and lymph node pDCs were collected from mice in different disease stages by using Nycodenz enrichment and sorting systems. Human pDCs from healthy donor and SLE patients were isolated by using BDCA4 beads selection. Mouse pDCs were stimulated with ODN2216 and Poly U for Tlr9 and Tlr7 respectively. Human pDCs were stimulated with ODN2216 and R837 for Tlr9 and Tlr7 respectively. After 18 hour for human and 36 hour for mouse, supernatant was collected for ELISA test. IFNa, TNFa, and IL6 were tested.

Results Bone marrow pDC could produce much higher IFNa than pDCs from spleen, thymus and lymph node in all tested strains. pDCs from NZB, NZBW F1 could produce higher IFNa than those from other strains. Spleen pDCs from MRL/ lpr and MRL/Mp mice could produce higher levels of IFNa via Tlr7 than Tlr9 stimulation. All lupus-prone mice except $\mathrm{BXSB} / \mathrm{Mp}$ and B6.SLE1.2.3 strains have higher total pDCs numbers. Cytokine-producing ability of pDCs were reduced in mice with advanced disease stage. pDCs from SLE patients could produce higher IFNa than those from a healthy donor. Conclusions Phenotype and function of pDCs were largely dependent on their genetic background. Activation and function alterations of pDCs were observed in a lupus model. Hyperactive of pDC from SLE patients may contribute to lupus pathogenesis.

\section{Microbiome, infections, probiotics and nutritional factors in autoimmunity}

\section{COFFEE CONSUMPTION AND CLINICAL OUTCOMES IN COLOMBIAN PATIENTS WITH SYSTEMIC LUPUS ERYTHEMATOSUS}

MA Alzate ${ }^{* 1} 1^{2} \mathrm{~F}$ Ochoa, ${ }^{1} \mathrm{P}$ Ortiz-Salazar, ${ }^{1} \mathrm{D}$ Hernandez-Parra, ${ }^{1} \mathrm{R}$ Pineda. ${ }^{1}$ ARTMEDICA, Clinical information group, Medellin, Colombia; ${ }^{2}$ Universidad CES, Public Health Group, Medellin, Colombia

\subsection{6/lupus-2017-000215.353}

Background and aims This study was performed to analyse the influence of coffee consumption on clinical outcomes in colombian patients with systemic lupus erythematosus (SLE). Methods A cross-sectional analytical study was conducted in 731 Colombian patients with SLE in whom coffee consumption and its frequency was assessed. Differences in clinical outcomes (i.e., cardiovascular disease, age-at-onset, organ damage, polyautoimmunity, acute activity determined by SLEDAI, and clinical remission) were determined between drinkers and nondrinkers, as well as by frequency of consumption. Association was examined by chi-square and multivariate regression analyses.

Results Sociodemographic and clinical characteristics of the patients are shown in table 1 . Out of a total of 731 patients, $70 \%$ were current coffee drinkers, $57 \%$ reported daily consumption, $10 \%$ weekly consumption and $3 \%$ monthly consumption. Coffee intake was found to be associated with SLE age at onset, cardiovascular disease and 6 months clinical remission (Table 2). According to the frequency of intake, daily consumption was associated to reduced risk of early ageat-onset and a positive association with 6 months clinical remission (OR: 0,45 95\% CI $0,25-0,81$ and OR: 1,55 95\% CI 1,07-2,25, respectively). No differences were found for organ damage, polyautoimmunity and acute SLE activity. Conclusions In Colombian SLE patients with coffee consumption, a reduced risk of early age-at-onset and cardiovascular disease was recognised. Also, a positive association with 6 month clinical remission was found. Due to the 
Abstract 353 Table 1 Sociodemographic and clinical characteristics of the SLE patients

\begin{tabular}{|c|c|c|c|}
\hline \multicolumn{2}{|c|}{ Characteristic } & Median & IQR \\
\hline \multicolumn{2}{|c|}{ Age (vears) } & 47 & 23 \\
\hline \multicolumn{2}{|c|}{ Educational level } & $\pi$ & 7 \\
\hline & & \multicolumn{2}{|c|}{$\%$} \\
\hline \multicolumn{2}{|c|}{ Gender (Female) } & \multicolumn{2}{|c|}{92,1} \\
\hline Avea & Uran & \multicolumn{2}{|c|}{91} \\
\hline \multirow[t]{7}{*}{ Ocupason } & Student & \multicolumn{2}{|c|}{5,6} \\
\hline & Unemployed & \multicolumn{2}{|c|}{3.6} \\
\hline & Rouse mad & \multicolumn{2}{|c|}{41,2} \\
\hline & Retred & \multicolumn{2}{|c|}{10,6} \\
\hline & Intelectual & \multicolumn{2}{|c|}{10,3} \\
\hline & Manual & \multicolumn{2}{|c|}{20,1} \\
\hline & Moed occupation & \multicolumn{2}{|c|}{8,6} \\
\hline \multirow{5}{*}{$\begin{array}{c}\text { Socioeconomical } \\
\text { status }\end{array}$} & 1 & \multicolumn{2}{|c|}{11,5} \\
\hline & 2 & \multicolumn{2}{|c|}{36,8} \\
\hline & 3 & \multicolumn{2}{|c|}{36,4} \\
\hline & 4 & \multicolumn{2}{|c|}{10,8} \\
\hline & 506 & \multicolumn{2}{|c|}{4,5} \\
\hline & nical manifestat & & \\
\hline
\end{tabular}

\begin{tabular}{|c|c|c|}
\hline \multirow[t]{3}{*}{ Age at onset } & Early (<20 years) & 16,3 \\
\hline & Moderate (20-50 years) & 66,6 \\
\hline & Late (P50 years) & 17,1 \\
\hline \multirow{5}{*}{$\begin{array}{l}\text { Cardovascular } \\
\text { disease }\end{array}$} & Any cause & 31,6 \\
\hline & Attenal hypertension & 28,6 \\
\hline & Thrombosis & 2,9 \\
\hline & Cerebrovascular disease & 1,9 \\
\hline & Coronary artery disease & 1,2 \\
\hline \multicolumn{2}{|l|}{ Organ damage } & 34,9 \\
\hline \multicolumn{2}{|c|}{ Polyautioimmunity } & 11,2 \\
\hline \multicolumn{2}{|c|}{ Acute activity by SLEDAI } & $\overline{11,1}$ \\
\hline \multicolumn{2}{|c|}{ 6-months clinical remission } & 752 \\
\hline
\end{tabular}

methodology of the study and its limitations, it is not possible to conclude a causal relationship. More studies must be done to clarify the influence of coffee in autoinmune disease.
Abstract 353 Table 2 Association between coffee consumption and clinical outcomes in SLE patients $(\mathrm{N}=731)$

\begin{tabular}{|c|c|c|c|c|c|c|c|}
\hline \multirow[t]{2}{*}{ Characteristic } & & \multicolumn{2}{|c|}{$\begin{array}{c}\text { Coffee } \\
\text { consumptio } \\
n\end{array}$} & \multirow[t]{2}{*}{$\begin{array}{l}\text { Chi- } \\
\text { square }\end{array}$} & \multirow[t]{2}{*}{ Pvalue } & \multirow[t]{2}{*}{ OR } & \multirow[t]{2}{*}{$95 \% \mathrm{Cl}$} \\
\hline & & Yes & No & & & & \\
\hline \multirow[t]{3}{*}{ Age at onset } & Early & 73 & 46 & \multirow{3}{*}{5,25} & \multirow{3}{*}{0,072} & 0,57 & $0,33-0,97$ \\
\hline & $\begin{array}{c}\text { Moder } \\
\text { ate }\end{array}$ & 346 & 141 & & & 0,88 & $0,56-1,37$ \\
\hline & Late & 92 & 33 & & & 1 & . \\
\hline \multirow{2}{*}{$\begin{array}{l}\text { Cardiovascular } \\
\text { disease }\end{array}$} & Yes & 148 & 83 & \multirow{2}{*}{5,46} & \multirow{2}{*}{$0,019^{\circ}$} & 0,67 & $0,48 \cdot 0,93$ \\
\hline & No & 363 & 137 & & & 1 & . \\
\hline \multirow[t]{2}{*}{ Organ damage } & Yes & 184 & 71 & \multirow{2}{*}{0,94} & \multirow{2}{*}{0,335} & 1,18 & $0,84 \cdot 1,65$ \\
\hline & No & 327 & 149 & & & 1 & $\cdot$ \\
\hline \multirow{2}{*}{$\begin{array}{l}\text { Polyautoimmu } \\
\text { nity }\end{array}$} & Yes & 58 & 24 & \multirow{2}{*}{0,03} & \multirow{2}{*}{0,86} & & $0,63 \cdot 1,73$ \\
\hline & No & 453 & 196 & & & 1 & . \\
\hline \multirow{2}{*}{$\begin{array}{l}\text { Acute activity } \\
\text { by SLEDAl }\end{array}$} & Yes & 52 & 29 & \multirow{2}{*}{1,41} & \multirow{2}{*}{0,23} & 0,74 & $0,46 \cdot 1,21$ \\
\hline & No & 459 & 191 & & & 1 & . \\
\hline \multirow{2}{*}{$\begin{array}{l}\text { 6.months } \\
\text { clinical } \\
\text { remission }\end{array}$} & Yes & 396 & 154 & \multirow[b]{2}{*}{4,64} & \multirow[b]{2}{*}{$0,031^{\circ}$} & 1,48 & $1,03 \cdot 2,10$ \\
\hline & No & 115 & 66 & & & 1 & $\cdot$ \\
\hline
\end{tabular}

\section{A COMPARATIVE ANALYSIS OF GUT MICROBIOTA BETWEEN SYSTEMIC LUPUS ERYTHEMATOSUS PATIENTS AND NON-AUTOIMMUNE CONTROLS: A SINGLE CENTRECENTER COHORT EXPERIENCE}

${ }^{1} \mathrm{~A}$ bankole*, ${ }^{2} \mathrm{X}$ Luo, ${ }^{2} \mathrm{Z}$ Husen. ${ }^{1}$ Carilion Clinic, Rheumatology, Roanoke, USA; ${ }^{2}$ Virginia Tech, Department of Biomedical Sciences and Pathobiology, Blacksburg, USA

\subsection{6/lupus-2017-000215.354}

Background and aims Systemic lupus erythematosus (SLE) is the prototypical systemic autoimmune disease, and is characterised by hyperactive immune cells and antibody production. Change in gut microbiota is associated with autoimmune diseases in animal and humans models. We hypothesised that similar changes would be seen in patients with lupus, and may be future therapeutic targets.

Methods 21 patients with SLE and 12 controls with no autoimmune disease were enrolled. Stool samples obtained, homogenised and the cells lysed with $0.1 \mathrm{~mm}$ sterile zirconia beads and a bead-beater. The DNA was extracted; V4 region of $16 \mathrm{~S}$ rRNA gene was amplified using PCR. The purified amplicons were sequenced bi-directionally. High-quality reads with Phred score of $\geq 20$ were obtained by using Quantitative Insights into Microbial Ecology. Chimeric sequences were identified with USEARCH and removed from analysis. Taxonomy was 